\title{
Inspired by the Paralympics: Effects of Empathy on Audience Interest in Para-Sports and on the Destigmatization of Persons With Disabilities
}

Communication Research 2018, Vol. 45(4) 525-553

(C) The Author(s) 2016

Reprints and permissions: sagepub.com/journalsPermissions.nav DOI: I0.II77/00936502I5626984 journals.sagepub.com/home/crx

@SAGE

\section{Anne Bartsch', Mary Beth Oliver², Cordula Nitsch³, and Sebastian Scherr ${ }^{\prime}$}

\begin{abstract}
Theories of eudaimonic entertainment and destigmatization concur to suggest that empathic feelings elicited by portrayals of Paralympic athletes can increase audience interest in para-sports and can lead to prosocial attitude change toward persons with disabilities in general. Three experiments were conducted to examine this dual, mutually reinforcing function of empathy in promoting public awareness and destigmatization. Participants watched television spots about the Paralympics that elicited different levels of empathy. As expected, structural equation modeling revealed indirect effects of empathy on audience interest, attitudes, and behavioral intentions that were mediated by elevation and reflective thoughts (Studies I and 2 ), and by feelings of closeness, elevation, and pity (Study 3). Mediation effects were positive for reflective thoughts, elevation, and closeness, but were negative for pity. Results are discussed with regard to problematic effects of pity, and concerns that elevating "supercrip" narratives might lead to negative perceptions of persons with disabilities in general.
\end{abstract}

\section{Keywords}

para-sports, eudaimonic entertainment, empathy, destigmatization, audience interest

\footnotetext{
'Ludwig Maximilians University Munich, Germany

2Pennsylvania State University, University Park, USA

${ }^{3}$ Heinrich Heine University Düsseldorf, Germany
}

\section{Corresponding Author:}

Anne Bartsch, Ludwig Maximilians University Munich, Oettingenstr. 67, Munich 80538, Germany.

Email: anne.bartsch@ifkw.Imu.de 
Within the 60 years of their existence, the Paralympic Games have grown from a small local competition for disabled athletes to one of the biggest sport events worldwide. At the 2012 Summer Paralympics in London, a total of 4,237 athletes from 164 countries competed in 20 sports. The London Paralympics set new records in terms of ticket sales and media coverage as well, including increases in hours of live coverage and broadcast areas (International Paralympic Committee, 2012). This surge in media coverage provides unique opportunities not only for raising public awareness about the sporting excellence of disabled athletes. The Paralympics also offer a suitable context for putting broader issues about social inclusion, equality, and participation of persons with disabilities on the public agenda (Darcy, 2010; Fitzgerald, 2012). These broader political implications found expression, for example, in the policy document "London 2012: A legacy for disabled people" published by the British government (Department for Culture, Media and Sport, 2010). The document highlights the importance of the Paralympic Games in creating long-term benefits, such as transforming the perception of disabled people in society, and promoting disability equality.

This article aims to elucidate underlying cognitive and emotional processes that might further these goals on two different levels: (1) by stimulating audience interest in para-sports and (2) by promoting prosocial attitude change toward persons with disabilities in general. Our overall prediction was that empathy would have a dual, mutually reinforcing effect in the destigmatization process in that it can stimulate both audience interest, and prosocial attitude change. Yet we are also aware of the complexities of empathic feelings, not all of which might be equally conducive to the process of destigmatization. While feelings of empathic closeness may foster social inclusion, pity might, in contrast, increase social distance. Moreover, feelings of admiration and elevation have been critically discussed in context of "supercrip" narratives that highlight disabled athletes' willpower to overcome obstacles and challenges (Berger, 2008; Hardin \& Hardin, 2004; Shapiro, 1993). While many authors agree that such elevating narratives can be deeply moving for the general public (hence generate audience interest), concerns have also been raised that "supercrip" narratives might establish unrealistic standards of comparison against which persons with disabilities in general may be unfavorably judged. In light of these promises and complexities of empathy in the context of the Paralympics coverage, it seems important to better understand its possible contribution and/or interference with the dual goal of raising audience interest and promoting attitude change toward persons with disabilities in general.

Prior research on the attractions of sports spectatorship has predominantly focused on hedonic motivations such as enjoyment and suspense (David, Horton, \& German, 2008; Raney, 2004). However, as Hall (2015) has recently argued, sports spectatorship can also be driven by more serious eudaimonic motivations such as individuals' search for insight, meaning, and social connectedness. Specifically, Hall found that basketball spectators perceived the game as meaningful, moving, and thought-provoking to the extent that they were involved with the sport, and experienced a sense of virtual friendship with the athletes. Like Hall, we think that research on sports spectatorship could profit from expanding its focus to the domain of more serious and contemplative 
viewing motivations and effects. The current research is a first attempt to examine the influence of eudaimonic experiences on audience interest and attitude change in the context of para-sports.

Three experiments were conducted, including a field experiment during the 2012 Summer Paralympics, using television spots that advertised the live coverage of the Games. Two versions of the spots were created to either amplify or diminish empathic feelings elicited by the content, so as to be able to examine the influence of empathy on different indicators of audience interest in para-sports, and on attitude change about persons with disabilities in general. In addition, we examined the mediating role of reflective thoughts, and of different subtypes of empathic feelings including elevation, closeness, and pity as explanatory mechanisms that might further qualify the general effects of empathy on audience interest and prosocial attitude change.

\section{Motivations of Sports Spectatorship: Hedonic and Eudaimonic Approaches}

Recent theoretical and empirical work in the field of media psychology (Oliver \& Bartsch, 2010; Oliver \& Raney, 2011; Tamborini, Bowman, Eden, Grizzard, \& Organ, 2010; Vorderer \& Reinecke, 2012; Wirth, Hofer, \& Schramm, 2012) has drawn attention to the distinction between two types of viewing experiences that can be intrinsically gratifying (i.e., experiences that attract audience interest independent of other goals and incentives than the viewing experience itself). On the one hand, media consumption can make individuals feel better immediately, for example, in terms of regulating mood and arousal, or by distracting the viewer from negative thoughts. This process of affect regulation through media use is thought to be the core of hedonic motivation (Knobloch-Westerwick, 2006; Zillmann, 1988). On the other hand, media consumption can also serve to stimulate rewarding social and cognitive experiences that contribute to emotional well-being in more complex and sustainable ways-for example, in that they foster a sense of insight, meaning, and social connectedness (Oliver \& Bartsch, 2010; Oliver \& Hartmann, 2010; Wirth et al., 2012). Based on the distinction in ancient philosophy between hedonic and eudaimonic happiness (i.e., happiness derived from pleasure, vs. happiness derived from meaning and insight), this second type of viewing motivations has been labeled eudaimonic motivation (Oliver \& Raney, 2011; Tamborini et al., 2010; Wirth et al., 2012). Both types of motivations, hedonic and eudaimonic, may contribute to the appeal of sports spectatorship in general, and to the appeal of para-sports in particular.

\section{Prior Research on Motivations of Sports Spectatorship: The Hedonic Approach}

Research on the attractions of televised sports in general suggests that hedonic entertainment functions are the most salient viewing motivation (for overviews, see David et al., 2008; Raney, 2004). Based on his literature review, Raney (2004) identified two main theoretical explanations for individuals' enjoyment of sports spectatorship. First, 
according to the affective disposition theory of sports spectatorship (Bryant \& Raney, 2000; Raney, 2004; Zillmann, Bryant, \& Sapolsky, 1989), individuals' fandom of specific athletes or teams is important in shaping their viewing experiences. Positive affect and enjoyment are experienced when positive outcomes are achieved by the viewer's favorite athlete or team, or when setbacks occur for the rivals. In particular, witnessing one's favorite athlete or team succeed in a competition, and sharing the winners' euphoric feelings can lead to high levels of enjoyment. Second, and related to the first point, viewing sports is often experienced as exciting and suspenseful, given the uncertainty of outcomes. The heightened level of arousal that accompanies suspense can serve to regulate aversive states of under-arousal and boredom, and can help distract viewers from negative thoughts (Raney, 2004).

Both theoretical frameworks share a common focus on hedonic mood regulation, either in terms of positive affect, or in terms of arousal. In the context of the growing popularity of some Paralympic athletes and teams, such hedonic aspects of sports spectatorship associated with fandom and suspense are likely to be experienced in the context of para-sports as well. In particular, viewers' identification with the athletes of their national Paralympic team may result in favorable affective dispositions that provide a basis for experiences of enjoyment and suspense. However, it seems unlikely that purely hedonic motivations account for the appeal of para-sports. According to Fitzgerald (2012), the combination of disabilities and excellent sports is often perceived as unfamiliar, due to the public image of sports that is strongly linked to imagery of bodily perfection (see also Kell, Kell, \& Price, 2008). Against the background of stereotypical expectations about bodily perfection, physical impairments of the athletes may appear more salient than their sporting abilities (Fitzgerald, 2012; Kell et al., 2008). In addition, viewers may be reminded about the vulnerability of the human life and body, a painful fact that is often elided in everyday life (Hirschberger, 2009). In this context, viewers of para-sports often seem to experience a mixture of positive and negative affect including responses such as sorrow, anxiety, or pity that may interfere with purely hedonic motivations (Fitzgerald, 2012; Florian, Mikulincer, \& Hirschberger, 2000).

\section{Eudaimonic Motivations: A Complementary View of Sports Spectatorship}

The concept of eudaimonic motivation (Oliver \& Raney, 2011) provides a complementary framework to the hedonic approach. It explains how media experiences with negative or mixed affective valence can nevertheless contribute to viewers' sense of meaningfulness and gratification. This line of research suggests that audiences are attracted to more serious, or even painful content, if such content is perceived to offer important insights about some aspect of the human condition (Bartsch, 2012; Knobloch-Westerwick, Gong, Hagner, \& Kerbeykian, 2013; Lewis, Tamborini, \& Weber, 2014; Oliver \& Hartmann, 2010; Tamborini et al., 2010; Wirth et al., 2012). For example, in a study on lessons learned from meaningful movies, Oliver and Hartmann (2010) found that viewers reflected on the value and fleetingness of life, the 
importance of human virtue and endurance, and the inevitability of sadness, cruelty, and pain as part of the human condition. In their analysis of eudaimonic entertainment experiences, Wirth et al. (2012) found five dimensions of eudaimonic gratification: (1) self-acceptance and purpose in life, (2) autonomy, (3) competence/personal growth, (4) relatedness, and (5) activation of central values.

In a sports context, athletes often seem to exemplify such core human values and virtues including willpower, self-sacrifice, and endurance in the face of obstacles and challenges. Consistent with this reasoning, Hall (2015) predicted and found that sports spectatorship can also be gratifying in terms of inspiring the viewer with meaningful and thought-provoking experiences. These contemplative experiences were in turn associated with empathic feelings (tender, inspired, compassion, touched, and moved), and were linked to spectators' involvement with the sport, and to their sense of virtual friendship with the athletes. Hence, a plausible but untested assumption is that eudaimonic gratifications can be experienced in the case of para-sports as well. Given that the biographies of disabled athletes often involve times of hardship, loss, and pain, their sporting excellence seems to exemplify what Oliver and Hartmann (2010) have identified as some of the most salient themes and lessons that viewers reportedly learned from meaningful media experiences-including the appreciation of human life as fleeting and precious, the value of mutual support, and the importance of human endurance and keeping faith during times of hardship and challenge. To cite some examples from the 2012 London Paralympics, Yohansson Nascimentos' finishing of the $100 \mathrm{~m}$ final, Xu Qings' world record in swimming, or Alexander Zanardis' comeback on a hand bike, are not only demonstrations of sporting excellence, they also highlight the athletes' dignity, and their willpower to overcome hardships and challenges in life. Thus, it can be assumed that in addition to hedonic motivations such as fandom and suspense, sports spectatorship may also be motivated by more contemplative, eudaimonic motivations.

\section{The Entertainment Experience: Hedonic Enjoyment and Eudaimonic Appreciation}

The distinction between hedonic and eudaimonic motivations for entertainment consumption has also been linked to qualitatively different types of entertainment experiences that arise from the satisfaction of these needs. Hedonically rewarding experiences that are characterized by positive valence and pleasant arousal such as amusement, thrill, and suspense, are usually subsumed under the concept of "enjoyment," whereas the experience of eudaimonic gratification has been conceptualized as "appreciation." Oliver and Bartsch (2010) defined eudaimonic appreciation as "an experiential state that is characterized by the perception of deeper meaning, the feeling of being moved, and the motivation to elaborate on thoughts and feelings inspired by the experience" (p. 76). This specific combination of affective involvement (being moved) and cognitive involvement (perception of meaning, motivation to elaborate) that is typical of eudaimonic appreciation seems to hold particular promise in terms of stimulating audience interest and promoting attitude change toward persons with disabilities. 


\section{Affective Responses Associated With Eudaimonic Appreciation}

Eudaimonic appreciation is typically associated with complex social emotions such as empathy (Oliver, Dillard, Bae, \& Tamul, 2012), elevation (Oliver, Hartmann, \& Woolley, 2012), tenderness (Oliver, 2008), being moved (Bartsch, Kalch, \& Oliver, 2014; Oliver \& Bartsch, 2010), and mixed affect (i.e., feeling happy and sad at the same time; Oliver \& Hartmann, 2010; Oliver, Hartmann, et al., 2012). This affective component of eudaimonic appreciation has been linked to prosocial media effects for several reasons.

A first line of evidence has shown that feelings of empathy can induce more positive attitudes toward members of a stigmatized group, and that they can stimulate altruistic motivation and helping behavior (Batson, Chang, Orr, \& Rowland, 2002; Batson et al., 1997; Oliver, Dillard, et al., 2012). Empathy is defined as "an other-oriented emotional response congruent with another's perceived welfare" (Batson et al., 1997, p. 105). The empathy-attitude model of Batson et al. (1997) assumes that empathic feelings toward an individual who is a member of a stigmatized group can lead to increased valuing of this individual's welfare. Assuming that the individual's plight is (partly) due to his or her membership in the stigmatized group, the altruistic motivation generalizes to the group as a whole and is reflected in more positive attitudes and desire to help the group.

Such destigmatizing effects of empathy are not limited to interpersonal interactions but seem to generalize to media portrayals of individuals who are part of stigmatized groups. For example, Oliver, Dillard, et al. (2012) found that empathic responses to narrative news formats resulted in more positive attitudes and behavioral intentions toward immigrants, prisoners, and elderly persons. Even empathic responses to fictional characters can be helpful to reduce stigmatization. As Ritterfeld and Jin (2006) have shown, empathy with a film character experiencing mental illness contributed to stigma reduction. A related line of research has examined destigmatizing effects of parasocial relationships with media characters - a concept that is closely related to empathy. Consistent with their parasocial contact hypothesis, Schiappa, Gregg, and Hewes (2005) found that exposure to gay male characters in television series resulted in more favorable attitudes toward gay men, especially for viewers who had strong parasocial relationships with the characters. Destigmatizing effects of parasocial relationships have also been found by Ortiz and Harwood (2007) for gay and Black characters, and by Hoffner and Cohen (2012) for a character with mental disability. Given this growing body of theoretical and empirical evidence concerning the role of empathy in stigma reduction, it can be assumed that empathic feelings elicited by portrayals of Paralympic athletes will contribute to the destigmatization of persons with disabilities in general as reflected in more positive attitudes and behavioral intentions toward this group (Hypothesis 1 [H1]).

In addition to their destigmatizing effect, empathic feelings have also been described as an intrinsically gratifying aspect of the eudaimonic entertainment experience (Bartsch, 2012; Bartsch et al., 2014; Oliver \& Bartsch, 2010). In this 
context, it is interesting to note that the self-report items used to measure empathy: "moved," "tender," "sympathetic," "warm," "softhearted," "compassionate" (Batson, Fultz, \& Schoenrade, 1987) are similar or even identical with self-report items representing the affective component of eudaimonic entertainment experience: "moved," "tender," "poignant" (Bartsch et al., 2014); "tender," "kind," "understanding," "sympathetic" (Oliver, 2008); or "tender," "inspired," "compassion," "touched," "moved" (Hall, 2015), suggesting that these items seem to tap closely related underlying constructs. If such empathy-related eudaimonic gratifications are obtained from viewing a media stimulus about the Paralympics, then individuals' motivation to follow the Paralympics media coverage should be heightened because of their expectation that similar gratifications can be obtained from similar media content. Therefore, we assume that empathic feelings elicited by portrayals of Paralympic athletes will contribute to audience interest in para-sports as reflected in higher reported interest in the Paralympics media coverage, and higher interest ratings of specific news articles about the Paralympics (Hypothesis $2[\mathrm{H} 2])$.

Taken together, $\mathrm{H} 1$ and $\mathrm{H} 2$ describe a dual, mutually reinforcing function of empathic feelings in the destigmatization process: As an intrinsically gratifying element of eudaimonic entertainment (Oliver \& Bartsch, 2010), empathic feelings can promote audience interest in para-sports - which in turn is a necessary precondition for the unfolding of attitudinal and behavioral effects of empathy as assumed by the empathy-attitude model (Batson et al., 1997).

\section{Pity, Closeness, and Elevation: The Complexities of Social Comparison Processes Involved in Different Subtypes of Empathic Feelings}

Although the general destigmatization effect of empathy is well supported by empirical evidence (Batson et al., 2002; Batson et al., 1997; Oliver, Dillard, et al., 2012), doubts have been raised about the conduciveness of specific subtypes of empathic feelings. Pity, for example, has been described as an ambivalent emotion (Fiske, Cuddy, Glick, \& Xu, 2002; Fitzgerald, 2012; Florian et al., 2000) that includes more than only prosocial tendencies such as compassion and desire to help. Through downward social comparison with others in need, pity can also involve negative aspects such as a sense of false superiority and social distancing (Fiske et al., 2002; Florian et al., 2000), which are counterproductive to the goal of reducing stigmatization and promoting social inclusion of persons with disabilities. For example, Fiske et al. (2002) found that the emotion of pity was typically associated with paternalistic stereotypes (i.e., stereotypes about out-groups perceived as likable but incompetent, including "elderly," "retarded," and "disabled" persons). Thus, in terms of destigmatization, pity can be characterized as a double-edged sword that may increase likability of the target group but can at the same time undermine perceptions of the group as competent and respectable. Preliminary evidence that pity can actually increase stigmatization comes from a study of Oliver et al. (2013) who found that feelings of pity 
had a marginally significant negative effect on attitudes toward persons with mental disabilities, whereas feelings of connectedness had a positive effect. Therefore, the general hypothesis about the destigmatizing effect of empathy needs to be qualified with regard to pity, such that empathy is counterproductive to the extent that it involves downward social comparison and pity. Hence, pity is assumed to constitute a negative mediator of the general effect (assumed in H1) of empathic feelings on the destigmatization of persons with disabilities (Hypothesis 3 [H3]).

According to Haidt (2003), "other-suffering" forms of empathy such as pity and compassion are but one type of empathic, other-oriented feelings (pp. 861-862). "Other-praising" emotions such as awe, admiration, and elevation share the same other-oriented and prosocial focus but involve upward social comparison processes instead.

Elevation can be conceptualized as a subtype of empathic, other-oriented feelings that is elicited "when witnessing acts of virtue or moral beauty" (Algoe \& Haidt, 2009, p. 106). The experience of elevation is typically associated with mixed affective responses, and with physical reactions such as tears, goose bumps, a lump in the throat, and a warmth or opening of the chest (Oliver, Hartmann, et al., 2012; Silvers \& Haidt, 2008). In motivational terms, elevation is associated with a desire to embody moral virtues (Aquino, McFerran, \& Laven, 2011; Oliver, Hartmann, et al., 2012), and with prosocial action tendencies (Aquino et al., 2011; Schnall, Roper, \& Fessler, 2010). Moreover, Fiske et al. (2002) found that feelings of admiration (that are akin to elevation) were typically associated with unequivocally positive stereotypes about social reference groups that were rated high on both warmth and competence (i.e., both liked and respected). Hence, compared with pity, elevation does not only provide a more apt description of responses to the extraordinary talent, courage, and willpower of Paralympic athletes, it also seems to bear promise in terms of social inclusion and destigmatization effects.

As noted in the introduction, however, the upward social comparison component of elevation has been considered with skepticism in the context of para-sports. Several authors (e.g., Berger, 2008; Hardin \& Hardin, 2004; Shapiro, 1993) have drawn attention to the double-edged nature of so-called "supercrip" narratives that highlight disabled athletes' heroic attitude and fighting spirit. Qualitative interviews with wheelchair athletes (Berger, 2008; Hardin \& Hardin, 2004) demonstrate the ambivalence associated with such narratives. On the one hand, many wheelchair athletes agreed that elevating narratives were instrumental in creating audience interest and "selling" para-sports to the general public. Some wheelchair athletes even found these narratives inspirational and empowering for themselves. On the other hand, however, many athletes voiced concern that these kinds of heroic narratives would set unrealistically high expectations for people with disabilities in general, and might suggest to the public that individual attitude and willpower could replace the necessity for social reforms.

Taken together, it seems relatively uncontroversial that feelings of elevation can help attract audience interest in para-sports - which is in line with research concerning the role of elevation as an intrinsically rewarding aspect of eudaimonic entertainment 
experience (Oliver \& Bartsch, 2011; Oliver \& Hartmann, 2010; Oliver, Hartmann, et al., 2012). Empathic feelings should be particularly conducive to audience interest to the extent that they involve the subtype of empathy that is characterized by upward social comparison and elevation. Hence, elevation is assumed to constitute a positive mediator of the general effect (assumed in H2) of empathic feelings on audience interest in para-sports (Hypothesis 4 [H4]).

Predictions concerning the effect of elevation on attitudes toward persons with disabilities in general are less clear.

Research Question 1 [RQ1]: Can feelings of elevation make a positive contribution to the destigmatization of persons with disabilities as suggested by general research on prosocial, destigmatizing implications of elevation (Aquino et al., 2011; Fiske et al., 2002; Oliver, Hartmann, et al., 2012; Schnall et al., 2010), or does elevation lead to unintended negative effects as assumed by the supercrip critique (Berger, 2008; Hardin \& Hardin, 2004; Shapiro, 1993)?

Most promising, perhaps, are feelings of empathic closeness, a third subtype of empathic feelings that involves social comparison at eye level. Feelings of closeness were not examined in Fiske et al.'s (2002) study, but it seems plausible to assume that such feelings are associated with positive in-group stereotypes (high likability and high respect). In line with this reasoning, Oliver et al. (2013) found that feelings of closeness (e.g., "caring," "closeness," "connection") had a positive effect on attitudes toward persons with mental disabilities (whereas pity had a negative effect as noted above). In a similar vein, Pavey, Greitemeyer, and Sparks (2011) found that priming a sense of relatedness had a positive effect on prosocial motivation and behavior. Hence, closeness is assumed to constitute a positive mediator of the general effect (assumed in $\mathrm{H} 1)$ of empathic feelings on the destigmatization of persons with disabilities (Hypothesis 5 [H5]).

\section{Cognitive Responses Associated With Eudaimonic Appreciation}

In addition to the experience of empathic feelings, eudaimonic appreciation is also associated with cognitive gratification factors such as the experience of insight, meaning, and cognitive challenge (Eden, Hartmann, \& Reinecke, 2015; Hartmann, 2013; Lewis et al., 2014; Oliver \& Bartsch, 2010). Other than hedonic enjoyment, which is characterized by a superficial, heuristic mode of cognitive processing, eudaimonic appreciation seems to promote a more elaborate style of information processing (Bartsch \& Schneider, 2014; Lewis et al., 2014). For example, eudaimonic entertainment has been found to encourage processes of deeper reflection, attitude change, and information seeking about social and political issues (Bartsch et al., 2014; Bartsch \& Schneider, 2014; Oliver, Dillard, et al., 2012; Oliver, Dillard, et al., 2012). The phrase "dual-process model of entertainment" that is increasingly used as a synonym for the hedonic/eudaimonic framework (Bartsch \& Schneider, 2014; Lewis et al., 2014; 
Vorderer \& Reinecke, 2012) highlights these parallels of entertainment theory with dual-process models of cognitive information processing (Chaiken, Liberman, \& Eagly, 1989; Lang, 2000; Petty \& Cacioppo, 1986).

One explanation why eudaimonic appreciation can motivate viewers to engage in cognitive elaboration has been proposed by Bartsch and Oliver (2011) based on the role of affective factors in motivating cognitive elaboration. Affective factors including negative valence, moderate arousal, and mixed affect have been shown to stimulate elaborate information processing, according to theories of motivated cognition such as the affect-as-information model (Schwarz \& Clore, 1988), the limited capacity model of motivated mediated message processing (Lang, 2000), and the moodas-a-resource model (Raghunathan \& Trope, 2002). In the context of eudaimonic entertainment, a recent line of research (Bartsch et al., 2014; Bartsch \& Schneider, 2014; Oliver et al., 2013) has found that the experience of feeling moved which is characterized by a combination of negative or mixed valence and moderate arousal can lead to more elaborate processing, prosocial attitude change, and further information seeking about the issues addressed in the moving media stimulus. As discussed above, measures of feeling moved and empathetic (Bartsch et al., 2014; Batson et al., 1987; Hall, 2015; Oliver, 2008) overlap to a substantial degree, and seem to tap closely related underlying constructs. Thus, the cognitively stimulating effect of feeling moved may serve as an additional mediator of the destigmatizing effect of empathy. Hence, we assumed that the effect of empathic feelings on the destigmatization of persons with disabilities in general (as predicted in H1) is mediated by reflective thoughts (Hypothesis 6 [H6]).

A similar mediation effect of reflective thoughts can be assumed with regard to audience interest, given that gratifications resulting from cognitive elaboration such as the experience of insight, meaning, and cognitive challenge have been shown to contribute to the audience appeal of eudaimonic entertainment (Bartsch \& Hartmann, 2016; Bartsch et al., 2014; Lewis et al., 2014). Moreover, being moved and experiencing reflective thoughts were associated with further information seeking about issues addressed in the moving media stimulus (Bartsch \& Schneider, 2014; Oliver et al., 2013). Therefore, we assume that the effect of empathic feelings on audience interest in para-sports (as predicted in $\mathrm{H} 2$ ) is mediated by reflective thoughts (Hypothesis 7 [H7]).

The hypotheses discussed above can be summarized in the form of three path models. The first model comprises the three hypotheses that deal with the influence of empathic feelings on audience interest in para-sports (H2), and with the role of elevation (H4) and reflective thoughts (H7) in mediating this relationship (see Figure 1). The second model considers the influence of the same set of variables, empathy (H1), elevation (RQ1), and reflective thoughts (H6), on the destigmatization of persons with disabilities in general (see Figure 2). The third path model involves a comparative analysis of elevation (RQ1), closeness (H5), and pity (H3) as potential mediators of the effect of empathic feelings (H1) on attitudes toward persons with disabilities in general (see Figure 3). 


\section{Method}

To examine these models, three experiments were conducted. Study 1 was a field experiment that was run during the 2012 Summer Paralympics to examine the influence of empathic feelings toward Paralympic athletes on audience interest. Participants watched a television spot advertising the Paralympics live coverage. Two versions of the spot were created that varied in terms of the background music (moving vs. neutral music) to either amplify or diminish the intensity of empathic feelings elicited by the visual content of the video. To minimize problems associated with prior exposure that would have made the music manipulation salient to participants, we presented German participants with a spot that was broadcast on a foreign television channel (Channel 4 in Great Britain). The experimental variation of empathic feelings using the music manipulation allowed us to examine the assumed influence of empathic feelings on audience interest in the Paralympics media coverage (H2), as well as the role of elevation (H4) and reflective thoughts (H7) in mediating this relationship. Self-reported interest in the Paralympics media coverage, and interest ratings of specific news articles about the Paralympics were assessed as indicators of audience interest.

Study 2 was conducted to investigate whether the effects of empathic feelings on audience interest examined in Study 1 would translate into changes in attitudes and behavioral intentions toward persons with disabilities in general. To address potential problems with stimulus-specific effects, two additional television spots about the Paralympics were included in the stimulus set and were subject to the same music manipulation using different pieces of moving and neutral music that have been pretested in prior research (Oliver et al., 2013). Participants were randomly assigned to view one of the six stimulus versions (three different trailers with either moving or neutral music). Measures of explicit and implicit attitudes toward persons with disabilities in general were assessed as indicators of destigmatization. Thus, we were able to examine the assumed influence of empathic feelings on the destigmatization of persons with disabilities (H1) as well as the role of elevation (RQ1) and reflective thoughts (H6) in mediating this relationship.

Study 3 was conducted to examine the mediating role of different subtypes of empathic feelings that involve different social comparison processes, including elevation (upward comparison, RQ1), closeness (comparison at eye level, H5), and pity (downward comparison, H3). The same stimulus set and dependent measures as in Experiment 2 were used except the time-consuming assessment of implicit attitudes via reaction time measures.

The music manipulation described above has been employed successfully in prior research (Bartsch et al., 2014; Bartsch \& Schneider, 2014; Oliver et al., 2013) to manipulate the affective component of eudaimonic appreciation, that is, the extent to which viewers felt moved and empathetic about otherwise identical media content. Of note, this stimulus design does not imply that music is assumed to constitute the sole elicitor of empathic feelings in the stimulus. Rather, the music manipulation is used to intensify empathic feelings aroused by the visual content (images and text elements) while keeping the cognitive, propositional content constant across experimental conditions. Manipulating the intensity of empathic feelings independently from cognitive 
content is a necessary requirement for testing the causal order of effects implied in our theoretical model where empathic feelings are considered as an independent variable that can intensify cognitive processes including reflective thoughts and social comparison processes implied in different subtypes of empathy such as elevation, closeness, and pity. It is important to note in this context that only one causal direction of influence (the effect of empathic feelings on other variables) can be tested with this experimental design, because the focus of the music manipulation is on the intensity of empathic feelings rather than on the manipulation of cognitive aspects of the stimulus. We acknowledge that the reverse causal order is equally plausible but beyond the scope of what we can test with our experimental design.

\section{Stimuli}

The three television spots about the Paralympics that were used as stimuli were 1.00, 1.30, and 1.44 minutes long, respectively. Two of the spots presented a collage of moving images that portrayed the athletes and the atmosphere of the games. The third spot showed a sprinter with a prosthetic leg running through a reenactment of biographic scenes representing his accident, surgery, and rehabilitation. In all spots, the images were combined with parsimonious text elements, highlighting the virtues exemplified by the athletes, including willpower, determination, and optimism facing obstacles and challenges. Except for the music manipulation, stimulus versions were identical in terms of images and text elements, so as to keep the propositional content constant across conditions and to avoid a confounding influence on cognitive aspects. For each spot, two versions were created using different background music. The background music included in the high empathy condition can be described as "moving" or "emotional," with a minor key, a slow tempo, and high variations in pitch. The music used in the low empathy condition was relatively neutral and unemotional (for pretest data concerning the background music, see Oliver et al., 2013).

A stimulus check was performed based on the data of Study 2 that included all three stimulus spots. A 2 (music type) $\times 3$ (spot) univariate ANOVA on ratings of empathic feelings was used to examine whether these spots elicited different levels of empathy. This analysis revealed a significant main effect of music type on empathy, $F(1,371)=$ 95.52, $p<.001, \eta_{\mathrm{p}}^{2}=.21$. However, there was no main effect of spot, $F(2,371)=0.00$, $p>.05, \eta_{\mathrm{p}}^{2}=.00$, and no interaction effect of music type by spot, $F(2,371)=0.39$, $p>.05, \eta_{\mathrm{p}}^{2}=.00$. Thus, the music manipulation was effective in creating stimulus conditions that elicited different intensity levels of empathic feelings. High empathy condition: Spot 1, $M=5.26, S D=1.12$; Spot 2, $M=5.24, S D=1.40$; Spot 3, $M=5.39$, $S D=0.97$; low empathy condition: Spot $1, M=3.95, S D=1.56$; Spot $2, M=3.85$, $S D=1.36 ;$ Spot 3, $M=3.81, S D=1.67$.

\section{Measures}

Empathic feelings: General empathy, elevation, closeness, and pity. Based on the theoretical background assumptions outlined above, four types of empathic feelings were assessed using self-report measures: (1) general indicators of empathy were based on 
items that were used in research on both empathy (Batson et al., 1987) and eudaimonic entertainment (Bartsch et al., 2014; Hall, 2015; Oliver, 2008): "moved," "tender," "poignant," "sympathy," and "compassion"; (2) elevation was represented by four items developed by Aquino et al. (2011) based on emotions described as indicators of elevation by Haidt (2003): "awe," "admiration," "inspired," and "compassion"; (3) closeness was represented by four items developed by Oliver et al. (2013): "closeness," "caring," "connection," and "compassion"; and (4) pity was represented by four items from the same study (Oliver et al., 2013): "pity," "sympathy," "sorry for," and "worried for." Ratings were recorded on a scale from $1=$ not at all to $7=$ very much. It is important to note that two items (sympathy and compassion) appeared redundantly in measures that were used in prior research to tap these constructs.

An exploratory factor analysis with varimax rotation requesting four factors was run to examine the discriminant validity of these items based on the data set of Study 3 that included all relevant items. This analysis revealed high and consistent factor loadings for three general indicators of empathic feelings: "moved," "tender," and "poignant" $(M=4.64, S D=1.55, \alpha=.90)$. "Sympathy" and "compassion" crossloaded on the pity factor and were therefore excluded from the general empathy scale. Three items had clear loadings on the elevation factor: "awe," "admiration," and "inspired" $(M=4.71, S D=1.42, \alpha=.75)$. Again, "compassion" cross-loaded on pity and was therefore excluded from the elevation scale. Three items clearly loaded on the closeness factor: "closeness," "caring," and "connection" $(M=3.42, S D=1.47, \alpha=$ .82). "Compassion" was excluded due to its cross-loading on pity. Finally, three items were chosen to represent the pity factor: "pity," "sorry for," and "worried for" ( $M=$ $2.87, S D=1.48, \alpha=.84)$. "Sympathy" and "compassion" were not included in the pity scale despite their primary loadings on this factor to avoid conceptual confusion about the underlying constructs measured by these scales, given that these items have been used in prior research to operationalize several other related constructs.

Reflective thoughts. Cognitive elaboration was assessed using eight statements about reflective thoughts that have been employed in prior research on eudaimonic appreciation (Bartsch, 2012; Bartsch, Kalch, \& Oliver, 2014), including "The spot inspired me to think about meaningful issues," "The spot made me think about myself," and "The spot helped me to better understand other people." Participants rated their agreement with these statements on a scale from $1=$ do not agree at all to $7=$ strongly agree. The eight items formed an internally consistent scale (Study 1: $M=3.00, S D=1.44, \alpha=$ .92 ; Study 2: $M=3.51, S D=1.50, \alpha=.89$ ).

Interest in the Paralympics media coverage. Three items were used to assess participants' interest in the Paralympics media coverage: "The spot makes me want to follow the Paralympics on television," "The spot makes me curious to learn more about the life stories of disabled athletes," and "The spot raised my interest in background information on para-sports" ( $1=$ do not agree at all to $7=$ strongly agree $)$. These items formed a consistent scale (Study 1: $M=3.32, S D=1.67, \alpha=.85$ ). In addition, participants were presented with three news articles about the Paralympics from the online edition of the German newspaper Die Zeit (415, 866, and 1,148 words, 
respectively) and were asked to rate how "interesting," "worthwhile," and "informative" they found these articles on a scale from $1=$ do not agree at all to $7=$ strongly agree. Participants were instructed to read as much of the articles as they would in a normal online news reading situation so as to simulate naturalistic interest ratings of news articles that are often based on incomplete reading. Across the three articles, ratings of "interesting," "worthwhile," and "informative" formed an internally consistent scale (Study 1: $M=4.95, S D=1.25, \alpha=.88$ ). Therefore, ratings were averaged across all three articles to form an overall measure of interest in news articles about the Paralympics.

Explicit attitudes toward persons with disabilities. Explicit attitudes toward persons with disabilities were measured using five items adapted from Batson et al. (1997). Examples of items include "In general, what are your feelings toward persons with disabilities?" and "Our society should do more to protect the welfare of persons with disabilities." The response scale ranged from 1 to 7 , with higher scores reflecting more favorable attitudes (Study 2: $M=5.17, S D=1.06, \alpha=.83$; Study 3: $M=5.10, S D=0.90, \alpha=.79$ ). In addition, participants completed the Attitudes Toward Disabled Persons Scale (ATDP; Yuker, Block, \& Younng, 1970). In this scale, the purpose of attitude measurement is covered up by seemingly caring but discriminatory statements such as "You should not expect too much from people with disabilities," or "You have to be careful what you say when you are with people with disabilities" (both reverse scored, response scale from 1 to 7 with higher scores reflecting more favorable attitudes). Two of the 20 items (Yuker et al., 1970; Items 3 and 8) lowered the reliability of the scale in Studies 2 and 3, and were therefore excluded from the scale. The remaining 18 items formed a consistent scale (Study 2: $M=5.32, S D=0.72, \alpha=.81$; Study 3: $M=5.35$, $S D=0.73, \alpha=.86)$.

Implicit attitudes toward persons with disabilities. Implicit attitudes were assessed using the Disability Attitude Implicit Association Test (DA-IAT; Pruett \& Chan, 2006). The DA-IAT is a reaction time test that measures participants' response latency when asked to sort stimuli that are related to persons with or without disabilities into the same category as words with positive or negative valence. By assessing the ease with which items are sorted into these categories, the DA-IAT provides an index of the relative strength of associations of disabled persons with positive versus negative words. Higher scores on this measure reflect more positive associations about persons with disabilities (Study 2: minimum $=-1.50$, maximum $=1.34, M=-0.36, S D=0.47$ ).

Behavioral intentions toward persons with disabilities. Behavioral intentions were assessed with four items using a modified version of Peng, Lee, and Heeter's (2008) measure (see Oliver et al., 2013) that taps participants' willingness to engage in different actions (e.g., sign a petition to build the political pressure needed to assist persons with disabilities; discuss the situation of persons with disabilities with their friends or family) 
using scales ranging from $1=$ not at all to $7=$ very much (Study $2: M=4.51, S D=$ 1.41, $\alpha=.78$; Study 3: $M=4.73, S D=1.33, \alpha=.78$ ).

\section{Study I}

Study 1 examined the effect of empathic feelings elicited by portrayals of Paralympic athletes on audience interest in the Paralympics (H2), and the possible role of elevation (H4) and reflective thoughts (H7) in mediating this relationship.

\section{Participants and Procedure}

Study 1 was conducted during the 2012 Summer Paralympics. In total, 322 participants were recruited from a noncommercial social science research panel in Germany. Of these participants, 19 had seen the original spot before and were therefore eliminated from the data set to avoid a confounding influence of prior knowledge, leaving 297 participants (126 male, 166 female, and five who did not indicate their gender, age: $M=33.34, S D=14.08$ ). The stimulus spot was embedded in an online questionnaire, with participants randomly assigned to see the spot either with moving, or with neutral music to elicit different levels of empathic feelings toward the Paralympic athletes portrayed. Subsequently, participants rated their level of general empathy, elevation, reflective thoughts, and interest in the Paralympics media coverage. In addition, they read and rated three news articles about the Paralympics that were presented to them at the end of the survey.

\section{Results}

To test H2, H4, and H7, structural equation modeling was performed using Mplus. The experimental manipulation served as the exogenous variable in the model; empathic feelings, elevation, and reflective thoughts served as mediators. The dependent variable, audience interest, was treated as a latent variable that was estimated from interest in the Paralympics media coverage, and interest ratings of the three news articles about the Paralympics. Maximum likelihood significance tests for indirect and total effects were estimated using bootstrapping procedures employing 2,000 bootstrap samples. In the model, error variances of the two mediator variables-elevation and reflective thoughts - were allowed to correlate. The estimated model showed a satisfying overall fit to the data $\left(\chi^{2}=7.35, d f=6, p=.29\right.$; root mean square error of approximation $[\mathrm{RMSEA}]=.03 ; \mathrm{p}$ of close fit $(\mathrm{PCLOSE})=.68$; comparative fit index $[\mathrm{CFI}]=1.00$; standardized root mean square residual $[\mathrm{SRMR}]=.03)$. All direct, indirect, and total effects in the model were significant at $p<.05$ (see Figure 1). As expected, the music manipulation had a direct effect on empathic feelings $(\beta=.29, p<.001)$ as well as a significant total effect on audience interest $(\beta=.13, p<.001)$; thus, H2 was supported. Furthermore, empathic feelings had a significant indirect effect on audience interest that was mediated by elevation $(\beta=.14, p<.05$; bootstrapped $95 \%$ confidence interval [CI] 
of indirect effect $=[.01, .26])$, supporting $\mathrm{H} 4$, and a significant indirect effect that was mediated by reflective thoughts $(\beta=.31, p<.001$; bootstrapped $95 \% \mathrm{CI}$ of indirect effect $=[.21, .41])$, supporting H7. However, there was also a significant direct effect of empathic feelings on audience interest $(\beta=.25, p<.01)$, indicating that the total effect of empathy on audience interest was based on a partial, complementary mediation (Zhao, Lynch, \& Chen, 2010) via elevation and reflective thoughts.

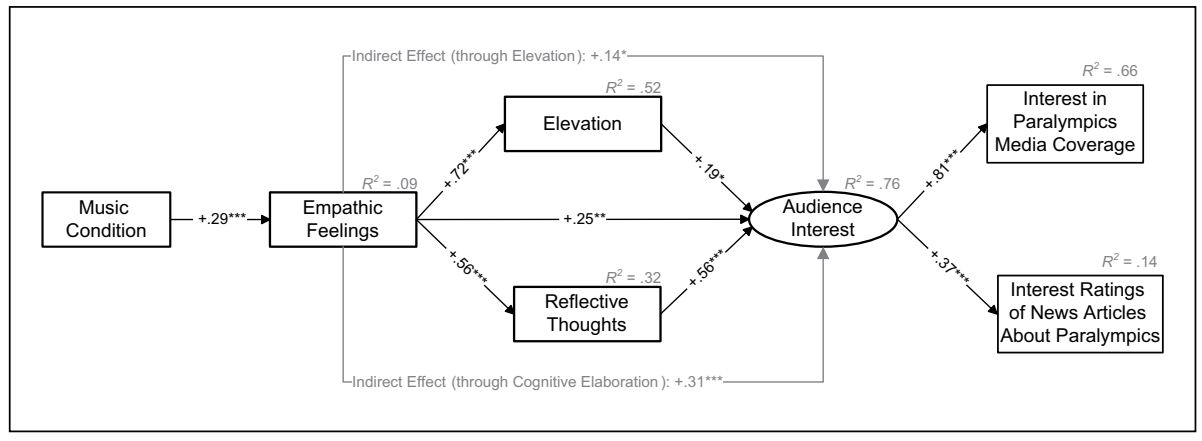

Figure I. Structural equation model of the influence of empathic feelings elicited by portrayals of Paralympic athletes on audience interest in the Paralympics, with elevation and reflective thoughts as mediators (Study I).

Note. $\chi^{2}=7.35, d f=6, p=.29 ;$ RMSEA $=.03 ;$ PCLOSE $=.68 ;$ SRMR $=.03 ; \mathrm{CFI}=1.00$. Standardized coefficients reported. RMSEA = root mean square error of approximation; SRMR = standardized root mean square residual; $\mathrm{CFI}=$ comparative fit index; $\mathrm{PCLOSE}=\mathrm{p}$ of close fit. $*_{p}<.05 . * *_{p}<.01 . * * * p<.001$.

\section{Brief Discussion of Study I}

Empathic feelings elicited by the stimulus spot varied as a function of the music manipulation. When combined with moving background music, the spot elicited higher levels of empathy. This experimental amplification of empathic feelings allowed us to examine the causal influence of empathy on audience interest in the Paralympics (H2), as well as the role of elevation (H4) and reflective thoughts (H7) in mediating this relationship. All three hypotheses were supported, suggesting that empathic feelings such as tenderness, poignancy, and being moved that are typically associated with eudaimonic entertainment are functional in stimulating audience interest in para-sports - especially to the extent that general empathy was associated with other-praising feelings such as elevation, and with processes of deeper reflection. However, an unexplained direct effect of empathic feelings on audience interest remained that was not attributable to either elevation or cognitive elaboration.

\section{Study 2}

The results of Study 1 indicate that eudaimonic gratification factors including empathy, elevation, and reflection played a significant role in stimulating audience interest 
in the Paralympics. Based on these findings, Study 2 examined whether such eudaimonic gratification factors would also be functional in terms of promoting changes in attitudes and behavioral intentions toward persons with disabilities in general. Specifically, we examined the influence of empathic feelings on the destigmatization of persons with disabilities (H1) as well as the role of elevation (RQ1) and reflective thoughts (H6) in mediating this relationship.

\section{Participants and Procedure}

Study 2 was conducted with an independent sample from the same noncommercial social science research panel in Germany $(N=708,289$ male, 419 female, age: $M=$ $38.61, S D=15.60)$. The stimulus spots were embedded in an online questionnaire that randomly assigned participants to view one of three spots with either moving or neutral music. As in Experiment 1, participants rated their level of general empathy, elevation, and reflective thoughts. In addition, self-report measures of explicit attitudes and behavioral intentions were assessed. Participants of Experiment 2 also completed the DA-IAT, which provides an implicit measure of attitudes toward persons with disabilities.

\section{Results}

To test H1 and H6, and to explore RQ1, structural equation modeling was performed using Mplus. The music manipulation served as the exogenous variable in the model, and empathic feelings, elevation, and reflective thoughts as mediators. The dependent variable, destigmatization, was estimated from measures of explicit and implicit attitudes, and behavioral intentions toward persons with disabilities. In the model, error variances of the two mediator variables - elevation and reflective thoughts - were allowed to correlate. The estimated model fit was acceptable $\left(\chi^{2}=73.50, d f=17, p<\right.$ $.001 ; \mathrm{RMSEA}=.07 ; \mathrm{PCLOSE}=.03 ; \mathrm{CFI}=.96 ; \mathrm{SRMR}=.05)$. All direct, indirect, and total effects in the model were significant at $p<.01$ except the direct effect of empathic feelings on destigmatization (see Figure 2). Specifically, the music manipulation had a direct effect on empathic feelings $(\beta=.21, p<.001)$ and a significant total effect on the latent destigmatization variable $(\beta=.07, p<.001)$; thus, H1 was supported. Empathic feelings had a significant indirect effect on destigmatization that was mediated by elevation $(\beta=.21, p<.001$; bootstrapped $95 \% \mathrm{CI}$ of indirect effect $=[.12$, .30]). Concerning RQ1, this positive mediation effect suggests that empathy was conducive to the destigmatization of persons with disabilities to the extent that it involved the subtype of empathic feelings associated with upward comparison and elevation. In addition, empathy had an indirect effect that was mediated by reflective thoughts $(\beta=$ $.13, p<.001$; bootstrapped $95 \% \mathrm{CI}$ of indirect effect $=[.07, .20])$, supporting H6. The direct effect of empathic feelings on destigmatization was not significant $(\beta=.01, p=$ $.87)$, indicating that the significant total effect of empathic feelings on destigmatization $(\beta=.34, p<.001)$ was based on an indirect-only mediation (Zhao et al., 2010) via elevation and reflective thoughts. 


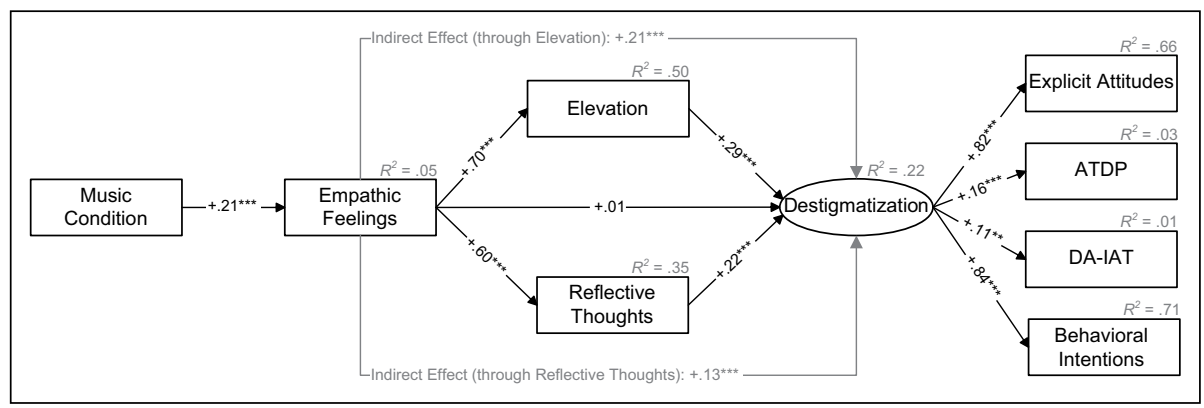

Figure 2. Structural equation model of the influence of empathic feelings elicited by portrayals of Paralympic athletes on destigmatization of persons with disabilities in general, with elevation and reflective thoughts as mediators (Study 2).

Note. $\chi^{2}=73.50, d f=17, p<.001 ;$ RMSEA $=.07$; PCLOSE $=.03 ;$ SRMR $=.05 ;$ CFI $=.96$. Standardized coefficients reported. ATDP $=$ Attitudes Toward Disabled Persons Scale; DA-IAT $=$ Disability Attitude Implicit Association Test; RMSEA = root mean square error of approximation; SRMR = standardized root mean square residual; $\mathrm{CFI}=$ comparative fit index; $\mathrm{PCLOSE}=\mathrm{p}$ of close fit.

$*_{p}<.05 . *_{p}<.01 . * * * p<.001$.

\section{Brief Discussion of Study 2}

Experiment 2 examined the causal influence of empathic feelings on destigmatizing attitudes and behavioral intentions toward persons with disabilities (H1), and the role of elevation (RQ1) and reflective thoughts (H6) in mediating this relationship. Both hypotheses were supported, and a positive mediation effect emerged for elevation, suggesting that empathic feelings associated with eudaimonic entertainment can contribute to the destigmatization of persons with disabilities - especially to the extent that empathy was linked with feelings of elevation and with reflective thoughts. The total effect of empathic feelings on destigmatizing attitudes and behavioral intentions was fully mediated by elevation and cognitive elaboration.

\section{Study 3}

The purpose of Study 3 was to examine the hypotheses and research question concerning the possible mediating role of three subtypes of empathic feelings that involve different social comparison processes including elevation (upward comparison, RQ1), closeness (comparison at eye level, H5), and pity (downward comparison, H3) on the destigmatization of persons with disabilities.

\section{Participants and Procedure}

Study 3 was conducted with a convenience sample recruited at three universities in Germany $(N=329,129$ male, 198 female, and two who did not indicate their gender, age: $M=24.36, S D=6.95)$. Again, three stimulus spots with either moving or neutral music were presented as part of an online questionnaire. Participants rated their level of general empathy, elevation, closeness, and pity. In addition, they rated their explicit attitudes and behavioral intentions toward persons with disabilities as in Study 2. 


\section{Results}

To examine H3 and H5, and RQ1, structural equation modeling was performed using Mplus. The music manipulation served as the exogenous variable in the model; empathic feelings, elevation, closeness and pity served as mediators. The dependent variable, destigmatization, was estimated from measures of explicit attitudes and behavioral intentions toward persons with disabilities. In the model, error variances of the three mediator variables - elevation, closeness, and pity - were allowed to correlate. Fit indices for the model indicated an acceptable fit to the data $\left(\chi^{2}=34.17, d f=14, p<.01\right.$; $\operatorname{RMSEA}=.07$; PCLOSE $=.16 ; \mathrm{CFI}=.97 ; \mathrm{SRMR}=.04)$. All direct, indirect, and total effects in the model were significant at $p<.05$ except the direct effect of empathic feelings on destigmatization (see Figure 3). Specifically, the music manipulation had a direct effect on empathic feelings $(\beta=.50, p<.001)$ and a significant total effect on the latent destigmatization variable $(\beta=.10, p<.01)$; thus, again, $\mathrm{H} 1$ was supported.

$\mathrm{H} 3$ assumed that the mediating effect of pity on destigmatization would be negative. The results indicated a significant negative mediation effect of empathic feelings on destigmatization via pity $(\beta=-.05, p<.05)$. The strongest positive mediator was closeness (H5) with a significant indirect effect of empathy on destigmatization via closeness $(\beta=.15, p<.001)$. The indirect effect mediated through elevation (RQ1) remained positive and significant $(\beta=.11, p<.05)$ when closeness and pity were included as additional mediators in the model but it was somewhat weaker than in Study 2. The direct effect of empathic feelings on destigmatization was not significant $(\beta=.09, p=.27)$, indicating that the significant total effect of empathic feelings on destigmatization $(\beta=.20, p<.001)$ was based on an indirect-only mediation (Zhao et al., 2010) via elevation, closeness, and pity.

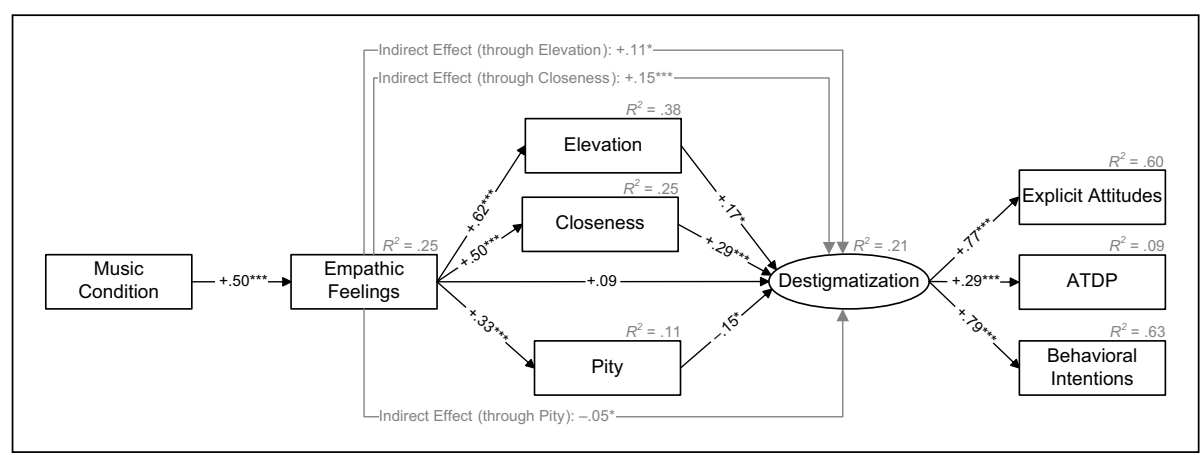

Figure 3. Structural equation model of the influence of empathic feelings elicited by portrayals of Paralympic athletes on destigmatization of persons with disabilities in general, with elevation, closeness, and pity as mediators (Study 3).

Note. $\chi^{2}=34.17, d f=14, p<.01$; RMSEA $=.07$; PCLOSE $=.16 ; \mathrm{CFI}=.97 ;$ SRMR $=.04$. Standardized coefficients reported. ATDP $=$ Attitudes Toward Disabled Persons Scale; RMSEA $=$ root mean square error of approximation; $\mathrm{CFI}$ = comparative fit index; SRMR = standardized root mean square residual; PCLOSE $=p$ of close fit.

$*_{p}<.05 . * * p<.01$. **** $p .001$. 


\section{Brief Discussion of Study 3}

The purpose of Study 3 was to follow up the findings of Study 2 about the destigmatizing effects of empathy and elevation. In addition to elevation, two other subtypes of empathic feelings (closeness and pity) were included as additional mediator variables to arrive at a more comprehensive understanding of how different subtypes of empathy contribute to, or detract from, the process of destigmatization. The positive mediation effect of elevation (RQ1) remained robust in this analysis, indicating that the mediating role of elevation was not reducible to other subtypes of empathic feelings such as closeness or pity. Among the three types of empathic feelings, the strongest positive mediation effect linking empathy and destigmatization was via feelings of closeness (H5). By contrast, the experience of pity which involves downward social comparison had a negative mediation effect (H3). That is, to the extent that the stimulus spots elicited pity, they seemed to increase rather than decrease the stigmatization of persons with disabilities. The findings indicate that all three types of empathic feelings served as independent mediators of the general effect of empathy on destigmatization, with positive mediation effects for closeness and elevation, and a negative mediation effect for pity.

\section{Summary and Concluding Discussion}

The purpose of the current project was to examine the dual, mutually reinforcing function of eudaimonic, empathy-eliciting media experiences in the process of destigmatization. First, given their role as intrinsically gratifying facets of eudaimonic entertainment experiences, empathy, elevation, and reflective thoughts elicited by television spots about the Paralympics were assumed to increase audience interest in the Paralympics media coverage.

Second, we considered the effects of the same set of eudaimonic entertainment factors (empathy, elevation, and reflective thoughts) on attitudes and behavioral intentions toward persons with disabilities in general. In particular, we were interested to explore the controversial role of elevation with regard to the destigmatization of persons with disabilities, given the concerns that have been voiced about potential negative effects of elevating "supercrip" narratives. Despite the presence of typical elements of "supercrip" narratives in our stimulus trailers that highlight Paralympic athletes' attitude and willpower, the findings indicate that feelings of elevation elicited by these trailers had a positive effect on the destigmatization of persons with disabilities in general. Of course, this finding needs to be treated with caution, because it might be specific to the limited set of three stimulus trailers used in our study. Nevertheless, it is promising to observe that at least in some cases of elevating media content, audience appeal and destigmatization effects seem to go hand in hand as they are based on the same underlying cognitive and affective processes.

The evidence supporting our core hypotheses about the general effect of empathy on audience interest in the Paralympics (Study 1), and the effect of empathy on the destigmatization of persons with disabilities (Studies 2 and 3), adds to a growing line 
of research on destigmatizing effects of moving, empathy-inducing media messages (Batson et al., 2002; Batson et al., 1997; Oliver, Dillard, et al., 2012; Oliver et al., 2013). In extension of the general effects of empathy on audience interest and destigmatization, several mediation effects were examined that provide further explication and specification of these general empathy effects.

First, the influence of empathy on both audience interest and destigmatization was mediated by reflective thoughts (Studies 1 and 2). This pattern of results extends an emerging line of research inspired by dual-process models of entertainment (Bartsch et al., 2014; Bartsch \& Schneider, 2014; Lewis et al., 2014; Oliver, Dillard, et al., 2012; Oliver, Hartmann, et al., 2012; Vorderer \& Reinecke, 2012). These models challenge widespread assumptions about the uniformly passive, escapist, and cognitively undemanding nature of entertainment by drawing attention to more serious, eudaimonic forms of entertainment experience that can encourage cognitive elaboration of the media content. The current findings add a new piece of evidence to dual-process models of entertainment by suggesting that the thought-provoking effect of eudaimonic, empathy-eliciting entertainment served as a critical mediator of prosocial attitude change. An important next step would be to examine whether such elaboration effects are also associated with stronger and more long-lasting attitude change - as predicted by the elaboration likelihood model (Petty \& Cacioppo, 1986). If the effects of cognitive elaboration in the context of eudaimonic entertainment turn out to be comparable with the cognitive elaboration of persuasive messages, eudaimonic entertainment would offer a particularly promising, long-lasting, and sustainable way of promoting changes in attitudes and behavior toward stigmatized groups.

Second, the influence of empathy on audience interest and destigmatization was mediated by a more fine-grained set of empathic feelings reflecting different types of social comparison processes, that is, elevation (upward comparison), closeness (comparison at eye level), and pity (downward comparison). The general concept of empathy which is defined as "an other-oriented emotional response congruent with another's perceived welfare" (Batson et al., 1997, p. 105) comprises all three subtypes of empathic feelings. Yet, despite a general sense of empathic benevolence associated with these feelings, the current findings highlight the necessity to distinguish between truly positive, destigmatizing forms of empathy such as elevation and closeness, and more ambivalent forms of empathy such as pity that can involve a sense of false superiority and social distancing. Our findings indicate that empathy was conducive to the destigmatization process to the extent that it involved feelings of elevation and closeness but that it was counterproductive to the extent that it involved feelings of pity.

The negative mediation effect of pity highlights important limitations of the empathy-attitude model of destigmatization (Batson et al., 1997) in that it draws attention to the ambivalent nature of pity. On the one hand, pity has been characterized as a prosocial emotion that shares an altruistic and benevolent core with other types of empathic feelings. But on the other hand, pity also involves an element of downward comparison and social distancing (Fiske et al., 2002; Florian et al., 2000) that works against destigmatization, perceived equality, and social inclusion of individuals who 
are part of a stigmatized group. In accord with Fiske et al.'s (2002) research, our findings suggest that pity can reinforce and perpetuate paternalistic stereotypes that characterize the stigmatized group as likable but incompetent and submissive. Thus, while pity may be functional in motivating some types of altruistic behavior such as charitable donation (Weiner, Perry, \& Magnusson, 1988), it seems less helpful in terms of promoting respectful attitudes and social inclusion of the stigmatized group on an equal footing.

The strongest positive mediation effect between general empathy and destigmatization was via feelings of closeness. That is, the destigmatizing effect of the stimulus spots was most pronounced when they left participants with a sense of empathic closeness - as expressed in open-ended statements of participants who observed that the Paralympic athletes were driven by the same dreams and passions, and that they experienced the same joy and pride about their success, or that participants would be interested to try out wheelchair sports themselves. This finding replicates and extends the results of Oliver et al. (2013) who found that the destigmatizing effects of moving stimulus spots about persons with mental illness or disability were mediated by feelings of empathic closeness. The correspondence of findings across two different types of stigmata is encouraging in that it substantiates the role of empathic closeness as a general underlying mechanism in the process of destigmatization. According to Hirschberger (2009), an effective way to reduce prejudices against persons with disabilities was to engage study participants in a cooperative task with a person sitting in a wheelchair. Although the media cannot replace the rich experience of actual social contact and cooperation, research on the parasocial contact hypothesis (Hoffner \& Cohen, 2012; Ortiz \& Harwood, 2007; Schiappa et al., 2005) has shown that individuals' sense of virtual friendship with media characters can have similar destigmatizing effects. An (admittedly speculative) explanation is that parasocial contact can encourage social comparison processes at eye level by highlighting the many ways in which persons who belong to the stigmatized group share the same experiences, goals, and concerns as the viewer himself or herself. This may help transform the perception of the stigmatized group from likable but incompetent paternalistic stereotypes (Fiske et al., 2002) to unequivocally positive in-group stereotypes characterized by both likability and competence.

In addition, the effect of general empathy on destigmatization was mediated via feelings of elevation. That is, the destigmatizing effect of the stimulus spots was enhanced by the extent to which participants responded with feelings of elevation to the human virtues and values exemplified by Paralympic athletes. This finding is relevant in view of concerns that heroizing "supercrip" narratives might reflect unfavorably on the perception of persons with disabilities in general who do not exhibit the same level of sporting excellence. Our results suggest that such concerns cannot be generalized to all types of elevating narratives in the context of the Paralympics media coverage. On the contrary, in the case of our data, human virtues and values exemplified by the Paralympic athletes such as optimism and willpower in facing hardships and challenges in life seemed to be generalized to the perception of persons with disabilities independent of the specific context of sports. Further research is necessary to 
examine the specific conditions under which these positive effects occur, but the findings are promising in that they suggest that some types of elevating narratives can be harnessed for the dual goal of attracting audience interest and promoting the destigmatization of persons with disabilities.

\section{Limitations}

Despite these promising findings and avenues for further research, several limitations of the current research need to be noted. First, our studies were based on a rather limited set of stimulus spots that served to advertise the live coverage of the Paralympic Games. In these spots, the moving and thought-provoking aspects of para-sports were highlighted by text elements and by aesthetic devices such as music, editing, slow motion, and inserts of images reminding the viewer about moments of loss and pain in the athlete's life. Thus, in the interest of increasing ecological validity with regard to actual viewership, it is important to further examine whether less aestheticized but longer forms of media coverage such as the television live coverage or news articles about para-sports can have similar destigmatizing effects. In particular, journalists might question the practical implications of the music manipulation employed in the current project given the limited scope of content where the use of background music is adequate. Therefore, further research using different types of experimental manipulations is needed to examine the influence of a broader range of content features that may contribute to the destigmatizing effects of empathic feelings, such as, for example, moving exemplars (Bartsch \& Schneider, 2014) or narrative news formats (Oliver, Dillard, et al., 2012). The limited evidence available suggests that story formats that focus on individual cases and encourage perspective taking are particularly likely to elicit empathy and prosocial responding (Bartsch \& Schneider, 2014; Batson et al., 2002; Batson et al., 1997; Oliver, Dillard, et al., 2012).

Second, it seems important to further examine the interplay of emotion and cognition in the process of destigmatization. As explained in the Method section, our experimental design was limited to one causal direction of effects, namely, the effect of empathic feelings on cognition. A reverse causal influence of cognition on empathic feelings is equally plausible, and needs to be examined to arrive at a more comprehensive understanding of possible reciprocal effects. For example, it would be worthwhile to study the influence of cognitive elaboration on social comparison processes implied in different subtypes of empathic feelings such as pity, closeness, and elevation. Likewise, Studies 1 and 2 examined elevation and cognitive elaboration in the same model, showing that both variables were associated with a reduction in stigmatization. However, future research should consider including the additional feelings of pity and closeness in the model as well, as that approach could elucidate the interplay between cognition and these additional two forms of empathy.

Third, the results are limited by the focus of the current research on a specific type of stigmata that is physical disabilities. As already noted, results of Oliver et al. (2013; Oliver, Dillard, et al., 2012) suggest that core findings concerning the destigmatizing effects of moving, empathy-inducing media content can be generalized to 
the destigmatization of other social groups, including persons with mental illnesses or disabilities, immigrants, prisoners, and elderly persons. It is important to note, however, that the effects associated with the three subtypes of empathy (pity, closeness, and elevation) might be specific to paternalistic stereotypes. Fiske et al. (2002) described two additional kinds of negative stereotypes: contemptuous prejudice (characterized by perceptions of low likability and low competence, for example, welfare recipients, poor people) and envious prejudice (characterized by perceptions of low likability and high competence, for example, Asians, Jews, rich people). In the case of contemptuous or envious stereotypes, pity could possibly be associated with destigmatizing effects, because it might counteract perceptions of low likability and group rivalry. Conversely, positive effects of upward comparison associated with elevation and admiration might be limited to low competence stereotypes (contemptuous and paternalistic prejudice) where admiration can counteract perceptions of dependency and submissiveness. However, in the case of high competence stereotypes such as envious prejudice, upward comparison might reinforce individuals' sense of envy and group rivalry. Therefore, further research is needed to investigate which subtypes of empathy are conducive to the destigmatization process in the case of different types of stigmatized groups.

A fourth limitation concerns the possible moderating role of individual dispositions. Our study design did not include individual differences such as participants' prior experience with watching para-sports, or their personal experience with persons with disabilities (including family members, friends, colleagues, etc.) that could have moderated the effects. Moreover, individuals' identification with their national Paralympic team could play an unexamined moderating role in shaping feelings of empathy and connectedness. The stimulus spots included in the current project were geared toward U.K. and Canadian audiences, focusing on national athletes; hence, for the German participants in our study, there was no basis for national identification.

Finally, the results are limited by the heavy weight of explicit attitudes and behavioral intentions as indicators of the latent destigmatization variable. The weak association between implicit and explicit measures of attitudes is in line with existing research (Thomas, Vaughn, Doyle, \& Bubb, 2014), and though weaker, the weight of implicit attitudes (DA-IAT; Pruett \& Chan, 2006) as an indicator of the latent destigmatization variable was significant and in the expected direction. One possible interpretation is that explicit attitudes are more easily controllable, and that changes in explicit attitudes therefore precede changes in deeply rooted implicit attitudes that are more difficult to control- even when individuals are willing to change. Another, less optimistic interpretation is that the stronger effects of empathy on explicit attitudes were due to socially desirable response tendencies. Given that images and textual elements were kept identical across conditions, propositional content was not a plausible source of social desirability effects. Yet, it cannot be ruled out that the moving music might have cued participants to the social desirability of positive attitudes toward persons with disabilities to a greater extent than the neutral music. To address this potential confound, further studies including measures of social desirability are needed as well as longitudinal designs that can elucidate the influence of explicit attitudes on implicit attitudes over time. 
With these limitations in mind, we think that the current results are encouraging in that they highlight the role of empathy, elevation, and reflective thoughts as common underlying factors that can stimulate both audience interest in para-sports and attitude change about persons with disabilities in general. This specific combination of cognitive and affective factors has recently been conceptualized under the rubric of eudaimonic entertainment (Oliver \& Bartsch, 2010; Oliver \& Raney, 2011; Wirth et al., 2012) and has been linked to positive media effects, including deeper reflection, information seeking, altruistic motivation, and attitude change about stigmatized groups (Bartsch et al., 2014; Bartsch \& Schneider, 2014; Oliver, Dillard, et al., 2012; Oliver, Hartmann, et al., 2012). The current research was an attempt to apply the logic of the eudaimonic entertainment concept to processes of destigmatization in the context of para-sports. The results suggest that this approach can be fruitful in that it highlights the possible contribution of more serious aspects of sports spectatorship to the goal of transforming the perception of disabled persons in society and promoting disability equality.

\section{Declaration of Conflicting Interests}

The authors declared no potential conflicts of interest with respect to the research, authorship, and/or publication of this article.

\section{Funding}

The authors received no financial support for the research, authorship, and/or publication of this article.

\section{References}

Algoe, S., \& Haidt, J. (2009). Witnessing excellence in action: The other-praising emotions of elevation, admiration, and gratitude. Journal of Positive Psychology, 4, 105-127. doi:10.1080/17439760802650519

Aquino, K., McFerran, B., \& Laven, M. (2011). Moral identity and the experience of moral elevation in response to acts of uncommon goodness. Journal of Personality and Social Psychology, 100, 703-718. doi:10.1037/a0022540

Bartsch, A. (2012). Emotional gratification in entertainment experience: Why viewers of movies and television series find it rewarding to experience emotions. Media Psychology, 15, 267-302. doi:10.1080/15213269.2012.693811

Bartsch, A., \& Hartmann, T. (2016). The role of cognitive and affective challenge in entertainment experience. Communication Research, 44, 29-53. doi:10.1177/0093650214565921

Bartsch, A., Kalch, A., \& Oliver, M. B. (2014). Moved to think: The role of emotional media experiences in stimulating reflective thoughts. Journal of Media Psychology, 26, 125-140. doi:10.1027/1864-1105/a000118

Bartsch, A., \& Oliver, M. B. (2011). Making sense of entertainment: On the interplay of emotion and cognition in entertainment experience. Journal of Media Psychology, 23, 12-17. doi:10.1027/1864-1105/a000026

Bartsch, A., \& Schneider, F. M. (2014). Entertainment and politics revisited: How non-escapist forms of entertainment can stimulate political interest and information seeking. Journal of Communication, 64, 369-396. doi:10.1111/jcom.12095 
Batson, C. D., Chang, J., Orr, R., \& Rowland, J. (2002). Empathy, attitudes, and action: Can feeling for a member of a stigmatized group motivate one to help the group? Personality and Social Psychology Bulletin, 28, 1656-1666. doi:10.1177/014616702237647

Batson, C. D., Fultz, J., \& Schoenrade, P. A. (1987). Distress and empathy: Two qualitatively distinct vicarious emotions with different motivational consequences. Journal of Personality, 55, 19-40. doi:10.1111/j.1467-6494.1987.tb00426.x

Batson, C. D., Polycarpou, M. P., Harmon-Jones, E., Imhoff, H. J., Mitchener, E. C., Bednar, L. L., . . Highberger, L. (1997). Empathy and attitudes: Can feeling for a member of a stigmatized group improve feelings toward the group? Journal of Personality and Social Psychology, 72, 105-118. doi:10.1037//0022-3514.72.1.105

Berger, R. J. (2008). Disability and the dedicated wheelchair athlete: Beyond the "supercrip" critique. Journal of Contemporary Ethnography, 37, 647-678. doi:10.1177/0891241607309892

Bryant, J., \& Raney, A. A. (2000). Sports on the screen. In D. Zillmann \& P. Vorderer (Eds.), Media entertainment: The psychology of its appeal (pp. 153-174). Mahwah, NJ: Lawrence Erlbaum.

Chaiken, S., Liberman, A., \& Eagly, A. H. (1989). Heuristic and systematic processing within and beyond the persuasion context. In J. S. Uleman \& J. A. Bargh (Eds.), Unintended thought (pp. 212-252). New York, NY: Guilford Press.

Darcy, S. (2010). The politics of disability and access: The Sydney 2000 Games experience. Disability \& Society, 18, 737-757. doi:10.1080/0968759032000119497

David, P., Horton, B., \& German, T. (2008). Dynamics of entertainment and affect in a Super Bowl audience: A multilevel approach. Communication Research, 35, 398-420. doi:10.1177/0093650208315965

Department for Culture, Media and Sport. (2010). London 2012: A legacy for disabled people. Setting new standards, changing perceptions. Retrieved from webarchive.nationalarchives. gov.uk/+/http:/www.culture.gov.uk/images/publications/GOE_London_2012_Disability_ Legacy.pdf

Eden, A., Hartmann, T., \& Reinecke, L. (2015). Tuning in versus zoning out: The role of egodepletion in selective exposure to challenging media. In H. Wang (Ed.), Communication and the "good life" (International Communication Theme Book Series, Vol. 2, pp. 107127). New York, NY: Peter Lang.

Fiske, S. T., Cuddy, A. J. C., Glick, P., \& Xu, J. (2002). A model of (often mixed) stereotype content: Competence and warmth respectively follow from perceived status and competition. Journal of Personality and Social Psychology, 82, 878-902. doi:10.1037/00223514.82.6.878

Fitzgerald, H. (2012). Paralympic athletes and "knowing disability." International Journal of Disability, Development and Education, 59, 243-255. doi:10.1080/1034912X.2012.697721

Florian, V., Mikulincer, M., \& Hirschberger, G. (2000). The anatomy of a problematic emotion: Conceptualizing and measuring of the experience of pity. Imagination Cognition and Personality, 19, 3-12. doi:10.2190/4jg9-m79p-hjyk-aqne

Haidt, J. (2003). The moral emotions. In R. J. Davidson, K. R. Scherer, \& H. H. Goldsmith (Eds.), Handbook of affective sciences (pp. 852-870). New York, NY: Oxford University Press.

Hall, A. E. (2015). Entertainment-oriented gratifications of sports media: Contributors to suspense, hedonic enjoyment, and appreciation. Journal of Broadcasting \& Electronic Media, 59, 259-277. doi:10.1080/08838151.2015.1029124

Hardin, M., \& Hardin, B. (2004). The "supercrip" in sport media: Wheelchair athletes discuss hegemony's disabled hero. Sociology of Sport Online, 7, 1-16. 
Hartmann, T. (2013). Media entertainment as a result of recreation and psychological growth. In E. Scharrer (Ed.) \& A. Valdivia (Gen. Ed.), Media effects/media psychology, Vol. 5: The international encyclopedia of media studies (pp. 170-188). Boston, MA: Wiley-Blackwell.

Hirschberger, G. (2009). Compassionate callousness: A terror management perspective on prosocial behavior. In M. Mikulincer \& P. R. Shaver (Eds.), Prosocial motives, emotion, and behavior: The better angels of our nature (pp. 201-219). Washington, DC: American Psychological Association.

Hoffner, C. A., \& Cohen, E. L. (2012). Responses to obsessive compulsive disorder on "Monk" among series fans: Parasocial relations, presumed media influence, and behavioral outcomes. Journal of Broadcasting \& Electronic Media, 56, 650-668. doi:10.1080/08838151. 2012.732136

International Paralympic Committee. (2012). London 2012. Retrieved from http://www.paralympic.org/london-2012

Kell, P., Kell, M., \& Price, N. (2008). Two games one movement? The Paralympic movement versus the Olympic movement. In K. Gilbert \& O. Schantz (Eds.), The Paralympic Games: Side show or empowerment? (pp. 155-166). Aachen, Germany: Meyer \& Meyer.

Knobloch-Westerwick, S. (2006). Mood management: Theory, evidence, and advancements. In J. Bryant \& P. Vorderer (Eds.), Psychology of entertainment (pp. 239-254). Mahwah, NJ: Lawrence Erlbaum.

Knobloch-Westerwick, S., Gong, Y., Hagner, H., \& Kerbeykian, L. (2013). Tragedy viewers count their blessings: Feeling low on fiction leads to feeling high on life. Communication Research, 40, 747-766. doi:10.1177/0093650212437758

Lang, A. (2000). The limited capacity model of mediated message processing. Journal of Communication, 50, 46-70. doi:10.1111/j.1460-2466.2000.tb02833.x

Lewis, R. J., Tamborini, R., \& Weber, R. (2014). Testing a dual-process model of media enjoyment and appreciation. Journal of Communication, 64, 397-416. doi:10.1111/jcom.12101

Oliver, M. B. (2008). Tender affective states as predictors of entertainment preference. Journal of Communication, 58, 40-61. doi:10.1111/j.1460-2466.2007.00373.x

Oliver, M. B., \& Bartsch, A. (2010). Appreciation as audience response: Exploring entertainment gratifications beyond hedonism. Human Communication Research, 36, 53-81. doi:10.1111/j.1468-2958.2009.01368.x

Oliver, M. B., \& Bartsch, A. (2011). Appreciation of entertainment: The importance of meaningfulness via virtue and wisdom. Journal of Media Psychology, 23, 29-33. doi:10.1027/1864$1105 / \mathrm{a} 000029$

Oliver, M. B., Dillard, J. P., Bae, K., \& Tamul, D. J. (2012). The effect of narrative news format on empathy for stigmatized groups. Journalism \& Mass Communication Quarterly, 89, 205-224. doi:10.1177/1077699012439020

Oliver, M. B., \& Hartmann, T. (2010). Exploring the role of meaningful experiences in users' appreciation of good movies. Projections, 4, 128-150. doi:10.3167/proj.2010.040208

Oliver, M. B., Hartmann, T., \& Woolley, J. K. (2012). Elevation in response to entertainment portrayals of moral virtue. Human Communication Research, 38, 360-378. doi:10.1111/ j.1468-2958.2012.01427.x

Oliver, M. B., Hoewe, J., Kim, K., Cooke, T., Shade, D., Bartsch, A., \& Kalch, A. (2013, November). Affective responses to media messages as a means of reducing stigmatization. Paper presented at the annual conference of the National Communication Association, Washington, DC.

Oliver, M. B., \& Raney, A. A. (2011). Entertainment as pleasurable and meaningful: Identifying hedonic and eudaimonic motivations for entertainment consumption. Journal of Communication, 61, 984-1004. doi:10.1111/j.1460-2466.2011.01585.x 
Ortiz, M., \& Harwood, J. (2007). A social cognitive theory approach to the effects of mediated intergroup contact on intergroup attitudes. Journal of Broadcasting \& Electronic Media, 51, 615-631. doi:10.1080/08838150701626487

Pavey, L., Greitemeyer, T., \& Sparks, P. (2011). Highlighting relatedness promotes prosocial motives and behavior. Personality and Social Psychology Bulletin, 37, 905-917. doi:10.1177/0146167211405994

Peng, W., Lee, M., \& Heeter, C. (2008, May). The influence of presentation mode on roletaking and empathic reaction: Playing a serious game vs. reading a news story about the Darfur crisis. Paper presented at the annual meeting of the International Communication Association, Montreal, Québec, Canada.

Petty, R. E., \& Cacioppo, J. T. (1986). The elaboration likelihood model of persuasion. Advances in Experimental Social Psychology, 19, 123-205. doi:10.1007/978-1-4612-4964-1_1

Pruett, S. R., \& Chan, F. (2006). The development and psychometric validation of the Disability Attitude Implicit Association Test. Rehabilitation Psychology, 51, 202-213. doi:10.1037/0090-5550.51.3.202

Raghunathan, R., \& Trope, Y. (2002). Walking the tightrope between feeling good and being accurate: Mood as a resource in processing persuasive messages. Journal of Personality and Social Psychology, 83, 510-525. doi:10.1037/0022-3514.83.3.510

Raney, A. A. (2004). Motives for using sport in the media: Motivational aspects of sport reception process. In H. Schramm (Ed.), Die Rezeption des Sports in den Medien [Sport reception in the media] (pp. 49-74). Köln, Germany: Herbert von Halem.

Ritterfeld, U., \& Jin, S.-A. (2006). Addressing media stigma for people experiencing mental illness using an entertainment-education strategy. Journal of Health Psychology, 11, $247-$ 267. doi:10.1177/1359105306061185

Schiappa, E., Gregg, P. B., \& Hewes, D. E. (2005). The parasocial contact hypothesis. Communication Monographs, 72, 92-115. doi:10.1080/0363775052000342544

Schnall, S., Roper, J., \& Fessler, D. M. T. (2010). Elevation leads to altruistic behavior. Psychological Science, 21, 315-320. doi:10.1177/0956797609359882

Schwarz, N., \& Clore, G. L. (1988). How do I feel about it? The informative function of mood. In K. Fiedler \& J. Forgas (Eds.), Affect, cognition, and social behavior (pp. 44-62). Toronto, Ontario, Canada: Hogrefe.

Shapiro, J. (1993). No pity: People with disabilities forging a new civil rights movement. New York, NY: Times Books.

Silvers, J., \& Haidt, J. (2008). Moral elevation can induce nursing. Emotion, 8, 291-295. doi:10.1037/1528-3542.8.2.291

Tamborini, R., Bowman, N. D., Eden, A., Grizzard, M., \& Organ, A. (2010). Defining media enjoyment as the satisfaction of intrinsic needs. Journal of Communication, 60, 758-777. doi:10.1111/j.1460-2466.2010.01513.x

Thomas, A., Vaughn, E. D., Doyle, A., \& Bubb, R. (2014). Implicit association tests of attitudes toward persons with disabilities. The Journal of Experimental Education, 82, 184-204. doi:10.1080/00220973.2013.813357

Vorderer, P., \& Reinecke, L. (2012). Zwei-Prozess-Modelle des Unterhaltungserlebens: Unterhaltung im Schnittbereich hedonischer und non-hedonischer Bedürfnisbefriedigung. [Dual-process models of entertainment experience: Entertainment at the intersection of hedonic and nonhedonic need satisfaction.] In L. Reinecke \& S. Trepte (Eds.), Unterhaltung in neuen Medien. Perspektiven zur Rezeption und Wirkung von Online-Medien und interaktiven Unterhaltungsformaten [Entertainment in the new media. Perspectives on the uses 
and effects of online media and interactive entertainment formats] (pp. 308-325). Köln, Germany: Herbert von Halem Verlag.

Weiner, B., Perry, R. P., \& Magnusson, J. (1988). An attributional analysis of reactions to stigmas. Journal of Personality and Social Psychology, 55, 738-748. doi:10.1037//00223514.55.5.738

Wirth, W., Hofer, M., \& Schramm, H. (2012). Beyond pleasure: Exploring the eudaimonic entertainment experience. Human Communication Research, 38, 406-428. doi:10.1111/ j.1468-2958.2012.01434.x

Yuker, H. E., Block, J. R., \& Younng, J. H. (1970). Measurement of Attitudes Toward Disabled Persons. Albertson, NY: INA Men Institute at Human Resources Center.

Zhao, X., Lynch, J. G., Jr., \& Chen, Q. (2010). Reconsidering Baron and Kenny: Myths and truths about mediation analysis. Journal of Consumer Research, 37, 197-206. doi:10.1086/651257

Zillmann, D. (1988). Mood management through communication choices. American Behavioral Scientist, 31, 327-340. doi:10.1177/000276488031003005

Zillmann, D., Bryant, J., \& Sapolsky, B. (1989). Enjoyment from sports spectatorship. In J. H. Goldstein (Ed.), Sports, games, and play: Social and psychological viewpoints (pp. 241-278). Hillsdale, NJ: Lawrence Erlbaum.

\section{Author Biographies}

Anne Bartsch ( $\mathrm{PhD}$, Martin Luther University Halle) is Professor at the Department of Communication Studies and Media Research at LMU Munich. She specializes in research on media uses and effects, with a focus on entertainment, emotional media effects, and the role of entertainment in political communication, health communication, and persuasion.

Mary Beth Oliver ( $\mathrm{PhD}$, University of Wisconsin) is Distinguished Professor and Co-Director of the Media Effects Research Laboratory at Penn State University. Her research focuses on media, emotion, and social cognition, with an emphasis on users' responses to entertainment and on positive media psychology.

Cordula Nitsch ( $\mathrm{PhD}$, University of Augsburg) is an assistant professor at the Institute of Social Science (Media and Communication Studies III), Heinrich-Heine University of Düsseldorf, Germany. Her research focuses on political communication, entertainment, fictional media content, and media effects.

Sebastian Scherr ( $\mathrm{PhD}$, LMU Munich) is a post-doctoral researcher at the Department of Communication Studies and Media Research, LMU Munich, Germany. His research focuses on media effects, political communication, health communication, suicide prevention, and empirical methods. 